\title{
Chapter 2 \\ Behavior of Radiocesium Adsorbed \\ by the Leaves and Stems of Wheat Plant \\ During the First Year After the Fukushima \\ Daiichi Nuclear Power Plant Accident
}

\author{
Keitaro Tanoi
}

\begin{abstract}
The behavior of radiocesium in winter wheat after the accident in March 2011 was characterized on the basis of an investigation of radiocesium in wheat grown in open fields. The distribution of the radiocesium contamination of wheat was analyzed by determining the radiocesium concentration in each part approximately 2 months after the fallout occurred in agricultural fields, which was a short period after the hydrogen explosion occurred at Fukushima Daiichi nuclear power plant. At that time, only the leaves and stems, but not the grains, were contaminated directly by the fallout because the wheat growing in the fields was in juvenile phase, before heading. The radioactivity was more than 1,000 times higher in the leaves growing at the time of the accident than that in the panicles that developed later. Autoradiographic images captured using an imaging plate showed that the highest radioactivity was found in many spots on the old leaves, suggesting that the radionuclides were strongly bound to the leaves. Moreover, effects of the seed sowing date, which varied from October 8th to November 20th, 2010, on the radiocesium concentration in grains were investigated. The radiocesium concentration in the grains after harvest was correlated with the plant height measured on May 28th. These results suggest that the radiocesium in the grains was derived from leaves and stems where it had accumulated when the fallout occurred.
\end{abstract}

Keywords Autoradiography • Contamination • Radiocesium $\bullet$ Wheat

\footnotetext{
K. Tanoi (四)

Graduate School of Agricultural and Life Sciences, The University of Tokyo,

1-1-1 Yayoi, Bunkyo-ku, Tokyo 113-8657, Japan

e-mail: uktanoi@mail.ecc.u-tokyo.ac.jp
} 


\subsection{Introduction}

In mid-March 2011, the fields in the east of Japan, particularly part of Fukushima Prefecture, were contaminated with radiocesium and radioiodine after an accident at the Fukushima Daiichi nuclear power plant. There are many reports of agricultural contamination by the fallout in the air, mostly related to nuclear bomb tests from 1940s to 1970s and the incident at Chernobyl. In these reports, transfer factor (TF) was used as an index of the degree of radionuclide transfer from the soil to the edible parts of crops. There are few data related to TF of radiocesium in wheat in Japan, although Uchida et al. (2007) reported that TF (dry-weight basis) of stable Cs in husked wheat was in the order $10^{-4}$ to $10^{-3}$.

The radiocesium concentration in husked wheat produced in 2011 in Fukushima Prefecture was measured, and most of the husked wheat was found to have an extremely low concentration of radiocesium, which was supported by the low TF of $\mathrm{Cs}$ in wheat. However, a high concentration of radiocesium, $>100 \mathrm{~Bq} / \mathrm{kg}$, was detected in a small proportion of the husked wheat in 2011. In general, direct contamination of the edible parts had the highest effect on the level of contamination in the edible parts. However, in this case, the grains were not directly contaminated by fallout because the wheat growing in the fields was in the juvenile phase, before heading. Thus, other mechanisms of radiocesium transfer to grains exist in addition to soil-to-plant (or grains) transfer and direct contamination of grains.

To understand the mechanism of radiocesium transfer to the grains in 2011, we used wheat plants that were growing in the open fields before the accident, in which we clarified the distribution of radiocesium contamination. The effects of the seed sowing date on the concentration of radiocesium in grains from the open field were also investigated.

\subsection{Materials and Methods}

\subsubsection{Analysis of Radiocesium in Each Plant Part}

The winter wheat cultivars "Kinuazuma," "Yukichikara," and "Abukumawase" were sowed directly $(0.7-\mathrm{m}$ furrow, $0.8 \mathrm{~kg} / \mathrm{a})$ on the wheat field (gray lowland soil; $\mathrm{N}: \mathrm{P}_{2} \mathrm{O}_{5}: \mathrm{K}_{2} \mathrm{O}=1: 1: 1 \mathrm{~kg} / \mathrm{a}$ as the basal fertilizer) in mid-fall, 2010. Ammonium acetate was used as a top-dressing at $0.3 \mathrm{~kg} / \mathrm{a}$ on February 25th, 2011. For monitoring the growth, the number of expanded leaves was counted for ten plants belonging to each cultivar.

Each plant part was collected on May 26th, 2011 (2 months after the fallout). Gamma ray analysis was performed using a germanium semiconductor detector for the "Kinuazuma" cultivar. The parts used in the analysis were the panicle, stem, flag leaf 1(FL1; the top of the flag leaf), FL2 (the leaf below FL1), FL3 (the leaf below FL2), and "other leaves" (older leaves). The samples were measured using a germanium semiconductor detector (GEM type, Seiko EG\&G). The gamma ray energies used to measure ${ }^{134} \mathrm{Cs}$ and ${ }^{137} \mathrm{Cs}$ activities were 604.7 and $661.6 \mathrm{keV}$, respectively. 
Autoradiography was performed for the three cultivars. Leaves from each position were collected and fixed onto Kent paper. After wrapping them in polypropylene film, the samples were exposed to an imaging plate (IP; BAS-IP MS2025, Fuji Film) for $7-10$ days at $-80{ }^{\circ} \mathrm{C}$. IP was scanned using a high performance image analyzer (FLA-5000, Fuji Film) at 100- $\mu$ m resolution with 16-bit data size and the data obtained was the photostimulated luminescence value.

\subsubsection{Effects of the Seed Sowing Date on the Radiocesium Concentration in Grains}

The wheat cultivar "Fukuakari" was sowed directly $(0.8 \mathrm{~kg} / \mathrm{a})$ on the wheat field (gray lowland soil; $\mathrm{N}: \mathrm{P}_{2} \mathrm{O}_{5}: \mathrm{K}_{2} \mathrm{O}=1: 1: 1 \mathrm{~kg} / \mathrm{a}$ as the basal fertilizer) on October 8 th, October 20th, November 8th, and November 20th, 2010. Ammonium acetate was used as a top-dressing at $0.3 \mathrm{~kg}(\mathrm{~N}) / \mathrm{a}$ on February 25th, 2011. The plant heights were measured on March 28th, 2011. The concentration of radiocesium in the grains was determined after harvest using a germanium semiconductor detector, as described in Sect. 2.2.1.

\subsection{Results and Discussion}

\subsubsection{The Radiocesium Was Tightly Bound to the Leaves That Had Already Expanded During the Fallout}

\subsubsection{The Concentration of Radiocesium in Each Plant Part Sampled from the Wheat Cultivar "Kinuazuma" on May 26th, 2011}

From the gamma spectra of the leaf samples, only radiocesium $\left({ }^{134} \mathrm{Cs}\right.$ and $\left.{ }^{137} \mathrm{Cs}\right)$ was identified as the fission products; therefore, the concentration of radiocesium was determined (Fig. 2.1).

The concentration of radiocesium was highest in "other leaves," and it declined drastically with the leaf position; the newest leaves contained the lowest radiocesium concentration. The panicles had the lowest concentration of radiocesium, which was more than $1 / 1000$ th of the "other leaves."

\subsubsection{Imaging Analysis of Radionuclides in Leaves from the Wheat Cultivars "Kinuazuma," "Yukichikara," and "Abukumawase" Sampled on May 26th, 2011}

Using the same samples that were analyzed by the germanium detector, we performed imaging analysis using IP to identify the distribution of radionuclides on the leaves. IP was more sensitive to beta rays than gamma rays, as is the case with 


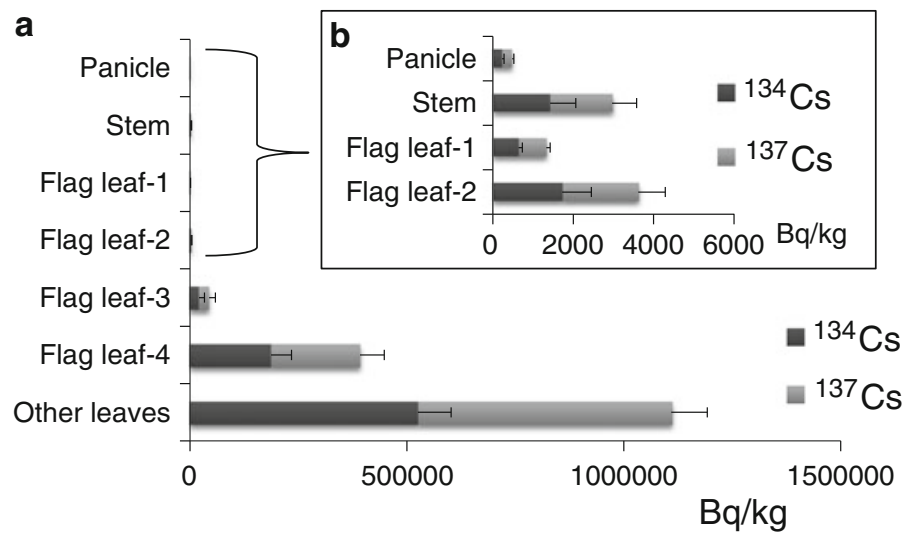

Fig. 2.1 The radiocesium concentration in the plant parts of the wheat cultivar "Kinuazuma" sampled on May 26th, 2011. (b) is an enlarged plot of (a), which contains the panicle, stem, FL1, and FL2. The error bars indicate the standard deviation $(n=3)$

positron emitters; the 511-keV gamma rays made little contribution to the IP analysis compared with the beta rays (Noguchi and Suzuki 2001). The possible beta-ray emitters of fission products and their daughters are ${ }^{131} \mathrm{I}$ (half life: 8.03 days), ${ }^{86} \mathrm{Rb}$ (18.6 days), ${ }^{134} \mathrm{Cs}$ (2.07 years), ${ }^{136} \mathrm{Cs}$ (13.16 days), ${ }^{137} \mathrm{Cs}\left(30.08\right.$ years), ${ }^{89} \mathrm{Sr}(50.53$ days), ${ }^{90} \mathrm{Sr}(28.79$ years $),{ }^{90} \mathrm{Y}(64 \mathrm{~h}),{ }^{91} \mathrm{Y}(58.51$ days $),{ }^{140} \mathrm{Ba}(12.75$ days $),{ }^{140} \mathrm{La}(1.68$ days), among others. From the analysis using the germanium detector, it is likely that the autoradiographic images indicated ${ }^{134} \mathrm{Cs}$ and ${ }^{137} \mathrm{Cs}$ in this study. It is also possible that ${ }^{90} \mathrm{Sr}$ contributed but this was considered to be low because the ratio of ${ }^{90} \mathrm{Sr} /$ radiocesium $\left({ }^{134} \mathrm{Cs}+{ }^{137} \mathrm{Cs}\right)$ was approximately $1 / 600-1 / 19000$ in soils sampled from the eastern part of Japan (http://radioactivity.mext.go.jp/ja/contents/6000/ 5808/24/194_Sr_0724.pdf: in Japanese). The contribution of ${ }^{40} \mathrm{~K}$, a natural beta-ray emitter, was considered to be trivial because there were no signals from a rice leaf without fallout contamination with 1 week contact with IP. There are a few reports of multi-nuclides being analyzed simultaneously and separately using shielding and image processing where the energies were significantly different from each other (Ishibashi et al. 2010). However, the high beta-ray energies emitted by both ${ }^{134} \mathrm{Cs}$ and ${ }^{137} \mathrm{Cs}$ meant that it was impossible to analyze them separately. Thus, it is suggested that the autographic images indicate the distribution of radiocesium.

The distribution of radiocesium is shown in Figs. 2.2 and 2.3. In Fig. 2.2, there are many active spots on FL4 and FL5, which were leaves that had already expanded by March 26th, 2011 (Table 2.1). On the other hand, there were hardly any spots on FL1, FL2, or FL3 (indicated as blue arrows), which had not emerged by March 26th, 2011 (Table 2.1). This indicated that the trend in the activities determined using the germanium detector and autoradiography were almost the same. The radiocesium distribution pattern captured by the imaging plate was also the same as the other cultivars ("Yukichikara" and "Abukumawase"), as indicated in Fig. 2.3 and Table 2.1. 


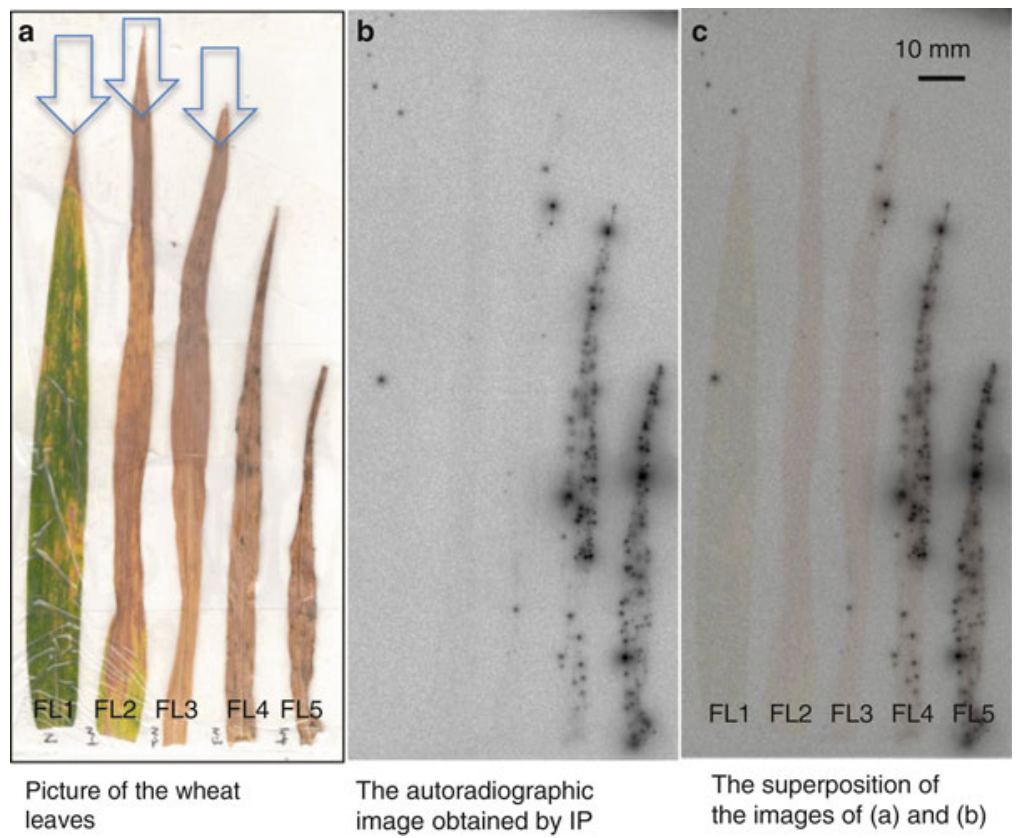

Fig. 2.2 Autoradiographic image of the wheat cultivar "Kinuazuma" obtained using an IP. The samples are from the same field as those shown in Fig. 2.1. "FL" indicates a flag leaf whereas the leaf positions are numbered from the top of FL to the bottom. The leaves indicated by blue arrows had not emerged by March 26th, 2011, which is also indicated in Table 2.1. The image (c) is a superposition of the images (a) and (b). There were three replicates for each analysis

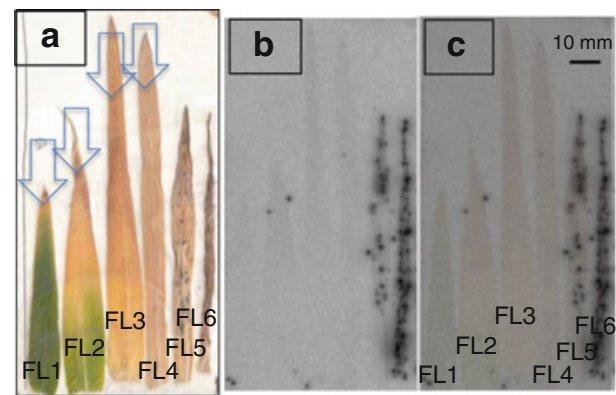

"Yukichikara"
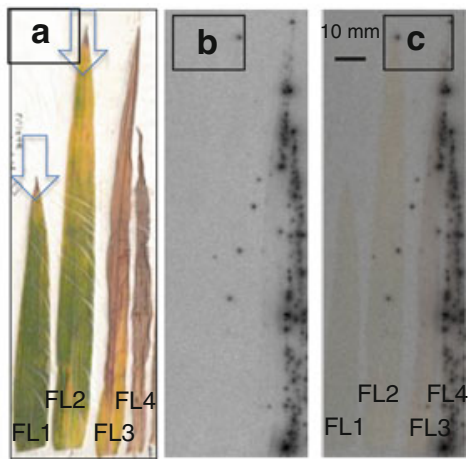

"Abukumawase"

Fig. 2.3 Autoradiographic images of the wheat cultivars "Yukichikara" and "Abukumawase" obtained using an IP. The samples were collected on the same day as "Kinuazuma," which is shown in Fig. 2.2. "FL" indicates a flag leaf and the leaf position is numbered from top to the bottom. The leaves indicated by blue arrows had not emerged by March 26th, 2011, which is also indicated in Table 2.1. (a) Shows the visible image, (b) is the autoradiographic image obtained using an IP, whereas image (c) shows a superposition of the images (a) and (b). There were three replicates for each analysis 
Table 2.1 The average number of expanded leaves of the wheat cultivars in March $2011(n=10)$

\begin{tabular}{|c|c|c|c|c|c|c|c|c|}
\hline & \multicolumn{2}{|c|}{ Number of expanded leaves } & \multicolumn{6}{|c|}{ Number of leaf position from bottom } \\
\hline & 1 March & 20 March & FL1 & FL2 & FL3 & FL4 & FL5 & FL6 \\
\hline "Kinuazuma" & 5.7 & 6.5 & 10 & 9 & 8 & $\underline{7}$ & $\underline{6}$ & $\underline{5}$ \\
\hline "Yukichikara" & 6.4 & 7.4 & 13 & 12 & 11 & 10 & 9 & $\underline{8}$ \\
\hline "Abukumawase" & 6.6 & 7.4 & 10 & 9 & $\underline{8}$ & $\underline{7}$ & $\underline{6}$ & $\underline{5}$ \\
\hline
\end{tabular}

The data were provided by Arai Y., Nihei N., Takeuchi M. and Endo A. in Fukushima Agricultural Technology Centre

The leaf number which is underlined, italic and bold type was expanded at the day of 20 March 2011 $F L$ flag leaf

Table 2.2 The growth and development of the wheats

\begin{tabular}{|c|c|c|c|c|c|c|c|}
\hline \multirow[b]{2}{*}{ Seeding date } & \multirow[b]{2}{*}{$\begin{array}{l}\text { Heading } \\
\text { date }\end{array}$} & \multirow[b]{2}{*}{$\begin{array}{l}\text { Ripening } \\
\text { date }\end{array}$} & \multicolumn{3}{|c|}{ Plant height $(\mathrm{cm})$} & \multirow{2}{*}{$\begin{array}{l}\text { No. of } \\
\text { spikes } \\
\left(\text { per } \mathrm{m}^{2}\right)\end{array}$} & \multirow{2}{*}{$\begin{array}{l}\text { Grain } \\
\text { weight } \\
\text { (kg/a) }\end{array}$} \\
\hline & & & 21 December & $28 \mathrm{March}$ & $\begin{array}{l}\text { Harvest } \\
\text { time }\end{array}$ & & \\
\hline 8 October & 7 May & 18 June & 31 & 34 & 73 & 561 & 58 \\
\hline 20 October & 8 May & 18 June & 14 & 19 & 75 & 634 & 74 \\
\hline 8 November & 13 May & 22 June & 9 & 9 & 71 & 502 & 70 \\
\hline 20 November & 15 May & 22 June & 5 & 7 & 72 & 551 & 68 \\
\hline
\end{tabular}

The data were provided by Arai Y., Nihei N., Takeuchi M. and Endo A. in Fukushima Agricultural Technology Centre

No. numbers

The analysis of the radiocesium concentration in each plant part showed that there was a significantly lower radiocesium concentration in the panicles that had not emerged in mid-March 2011, whereas a high concentration of radiocesium was detected on the leaves that had already expanded by mid-March 2011 when the fallout from the accident occurred. The spotty contamination on the leaves remained for up to 2 months after the fallout. These results suggested that the contamination, which was assumed to have been caused by radiocesium, was bound tightly to the surfaces of the leaves, whereas an extremely small amount of radiocesium entered the leaves and translocated to the panicles. The chemical form of caesium on the surfaces of leaves was not determined.

\subsubsection{The Plant Size at the Time of the Fallout in Mid-March 2011 Was the Main Factor That Affected the Radiocesium Concentration in Grains}

The growth parameters in the field are shown in Table 2.2. The plant height was more when the seeds were sown earlier. After the hibernation period, the plants from the October 20th sowing showed the most vigorous growth of the four different seeding dates. The differences in the heading and ripening dates for the different sowing dates varied by 8 and 7 days, respectively. 
Table 2.3 The concentration of radiocesium in grains

\begin{tabular}{lrcl}
\hline & \multicolumn{2}{l}{ Radiocesium in grain after harvesting } \\
\cline { 2 - 4 } Seeding date & ${ }^{134} \mathrm{Cs}(\mathrm{Bq} / \mathrm{kg})$ & ${ }^{137} \mathrm{Cs}(\mathrm{Bq} / \mathrm{kg})$ & Total radiocesium $(\mathrm{Bq} / \mathrm{kg})$ \\
\hline 8 October 2010 & 129 & 154 & 283 \\
20 October 2010 & 68 & 77 & 145 \\
8 November 2010 & 11 & 13 & 24 \\
20 November 2010 & 7 & 8 & 15 \\
\hline
\end{tabular}

a

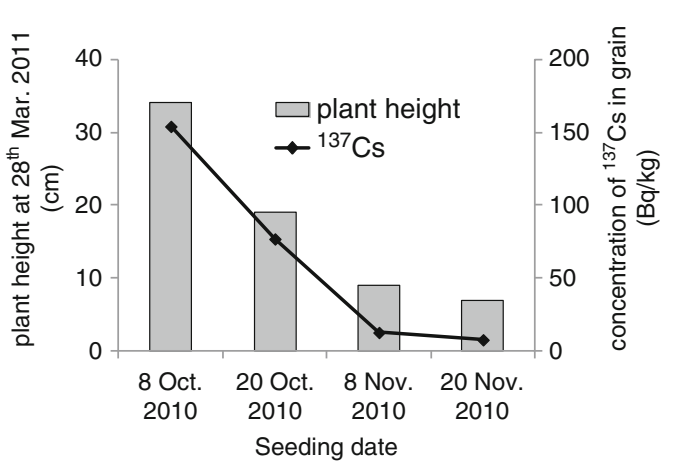

b

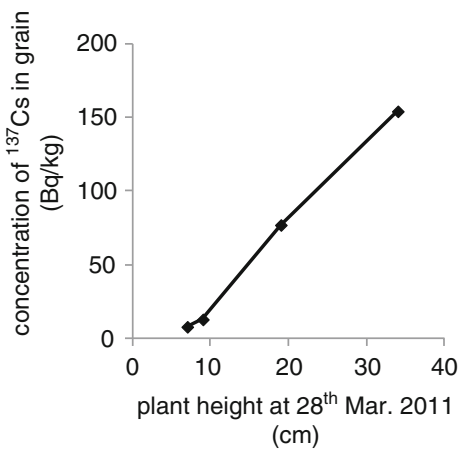

Fig. 2.4 (a) The relationship between the plant height on March 28th, 2011 (shown as grey bar) and the concentration of ${ }^{137} \mathrm{Cs}$ in the grains during harvest (shown as a polygonal line). (b) Plot of the plant height vs the concentration of ${ }^{137} \mathrm{Cs}$ in the grains. These data were provided by Arai Y., Nihei N., Takeuchi M. and Endo A. at the Fukushima Agricultural Technology Centre

The concentration of radiocesium in the grains decreased with the date of sowing (Table 2.3 and Fig. 2.4). The relationship among the sowing day, the plant height in mid-March 2011, and the ${ }^{137} \mathrm{Cs}$ concentration in the grain after harvesting is shown in Fig. 2.4. The ${ }^{137} \mathrm{Cs}$ concentration in the grain after harvesting was correlated with the plant height on May 28th, 2011 (Fig. 2.3b). The results strongly suggest that the radiocesium in the grain was derived from the leaves and stems that had already emerged by mid-March 2011, when the fallout occurred.

Komamura et al. (2006) reported that wheat grains in Japan were directly contaminated by fallout from the Chernobyl disaster and the concentration of ${ }^{137} \mathrm{Cs}$ in grain was higher than that in rice because heading had not occurred in rice plants by the end of April, when the disaster occurred. In wheat, there was a strong correlation between the date of head emergence and the concentration of ${ }^{137} \mathrm{Cs}$ in the grains (Komamura et al. 2006). For radiocesium, these reports indicate that there was a greater impact from the direct contamination of grains than indirect contamination which occurred through its transport from the soil to the edible parts of plants. Thus, the present study demonstrated the behavior of radiocesium in the leaves and/or stems and that it was transferred to the grains. This mechanism was the primary factor that determined the relatively high concentration of radiocesium in the grains produced in 2011. 
Open Access This article is distributed under the terms of the Creative Commons Attribution Noncommercial License which permits any noncommercial use, distribution, and reproduction in any medium, provided the original author(s) and source are credited.

\section{References}

Ishibashi H, Yamawaki M, Hirose A, Noda A, Kanno S, Saito T, Masuda S, Seyama S, Tanoi K, Nakanishi TM (2010) Double-tracer radiography with sulfur-35 and phosphorus-32 using imaging plates in Brassica napus L. Radioisotopes 59:75-79

Komamura M, Tsumura A, Yamaguchi N, Fujiwara H, Kihou N, Kodaira K (2006) Long-term monitoring and analysis of ${ }^{90} \mathrm{Sr}$ and ${ }^{137} \mathrm{Cs}$ concentrations in rice, wheat and soils in Japan from 1959 to 2000. Bull Natl Inst Agro Environ Sci 24:1-21

Noguchi J, Suzuki K (2001) Imaging plate characteristics of positron emitters: ${ }^{11} \mathrm{C},{ }^{13} \mathrm{~N},{ }^{15} \mathrm{O},{ }^{18} \mathrm{~F}$ and ${ }^{38} \mathrm{~K}$. Radiochem Acta 89:433-437

Uchida S, Tagami K, Hirai I (2007) Soil-to-plant transfer factors of stable elements and naturally occurring radionuclides (1) upland field crops collected in Japan. J Nucl Sci Technol 44(4): 628-640 